\title{
Territorios agrarios y realidades rururbanas. Reflexiones sobre el desarrollo rural a partir del caso pampeano bonaerense $e^{* * * *}$
}

\begin{abstract}
The debate on rural development has undergone a strong renewal due to transformations in agriculture, and in rural economies and societies. In this context, a broader vision of the rural medium has been observed, which includes rururban spaces where services and supply chains relating to local and regional production and consume are located. Of particular importance are non-agricultural occupations as additional income sources for rural homes. This paper explores these issues in the province of Buenos Aires - the main area of agricultural production in the pampeana region of Argentina-. Some of the features analyzed here are population trends and the rural-urban configuration; the characteristics of the territories that are potential or real bases for pluriactive strategies by the rural population; and the characteristics of the institutional webs that accompany redefinitions of territorial governance. In light of these elements, some issues for reflection are introduced in terms of the formulation of rural development policies.
\end{abstract}

Key words: rural territories, rururban spaces, non-agricultural occupations, rural territorial development, rural development policies, Province of Buenos Aires

\section{Resumen}

El debate sobre el desarrollo rural ha sufrido una fuerte renovación derivada de las transformaciones de la agricultura, y de las economías y sociedades rurales. En este contexto, se observa una visión ampliada del medio rural integrando complejos rururbanos de encadenamientos relacionados con la producción y el consumo local-regional, destacándose además la importancia de las ocupaciones no agrícolas como fuente de ingresos adicionales de hogares rurales. Este artículo explora estos aspectos en la provincia de Buenos Aires, principal espacio agroproductivo de la región pampeana argentina. Se examinan la combinación de las tendencias poblacionales y de la configuración rural-urbana; las características de los territorios que son asiento real o potencial de estrategias pluriactivas de la población rural; los entramados institucionales que acompañan redefiniciones en la governance de estos territorios. A la luz de estos elementos, se presentan algunos puntos de reflexión para la formulación de políticas de desarrollo rural.

Palabras clave: territorios rurales, espacios rururbanos, empleos rurales no agrícolas, desarrollo territorial rural, políticas de desarrollo rural, Provincia de Buenos Aires. 


\section{Introducción}

$\mathrm{D}$ esde hace un tiempo el análisis de la cuestión rural atraviesa una fuerte renovación teórica e instrumental. Por un lado, las transformaciones y modernización de la agricultura han llevado a visualizar el quiebre en la relación entre la producción agraria, su organización social y espacial, y el desarrollo rural. Por otro lado, la acelerada urbanización de la población replantea conceptualizaciones y abordajes del medio rural integrando la dimensión territorial (rururbana) en sus múltiples dinámicas y aspectos (ambientales, políticos, sociales, económicos, etc.).

En este marco, se producen reformulaciones en el paradigma del desarrollo rural que han llevado a la más reciente postulación del enfoque del Desarrollo Territorial Rural (DTR). Las propuestas de políticas que emanan de este enfoque sostienen: una visión amplia de las economías rurales, integrando complejos rururbanos de encadenamientos de servicios e insumos relacionados con la producción y el consumo local-regional; la importancia de las ocupaciones no agrícolas como fuente de ingresos adicionales de los hogares rurales pobres; y la necesidad de pasar a un proceso abierto de coordinación económica, social y política entre la multiplicidad de actores e intereses (públicos y privados) que intervienen en los procesos de desarrollo.

Entre estos lineamientos y la realidad rururbana de la provincia de Buenos Aires existe, sin embargo, un paso no menor, sobre todo, a la hora

Magíster en Economía, Investigadora del CONICET, Profesora del Departamento de Economía de la Universidad Nacional del Sur, Argentina. E-mail: sgoren@criba.edu.ar.

Economista, tesista Maestría en Desarrollo y Gestión Territorial, Universidad Nacional del Sur, Argentina. Email:mjnapal@yahoo.com.ar.

Economista, becaria CONICET, Departamento de Economía Universidad Nacional del Sur, Argentina. Email:molea@uns.edu.ar.

Trabajo realizado en el marco del Proyecto "Innovación, instituciones y governance en tramas agroalimentarias del sur pampeano"/subsidio del Programa Grupo de Investigación-UNS. Enviado el 13 de marzo de 2007, aprobado el 24 de julio de 2007. de vincular las condiciones económicas locales que conspiran contra la pluriactividad de los pequeños productores y el trabajo rural (agrícola y no-agrícola). Estas condiciones se alejan bastante tanto de la imagen estilizada que a menudo surge de la experiencia europea como de las modalidades de empleo u ocupaciones de la ruralidad campesina latinoamericana; tampoco parece asimilable al de las economías locales poco integradas y el sector de empresas informales que muestra buena parte de la evidencia empírica de los estudios de caso en América Latina.

El objetivo del presente trabajo es el de reflexionar, a partir de la consideración de recientes resultados de un estudio realizado en el medio rural bonaerense, sobre obstáculos existentes para el desarrollo territorial rural ${ }^{1}$. Se pone el acento en la configuración rural-urbana, analizando características de los territorios que son asiento real o potencial de estrategias pluriactivas de la agricultura familiar y de los entramados institucionales que acompañan ciertas redefiniciones en la governance de los territorios rurales.

Una lectura analítica que, en esencia, está guiada por dos grandes interrogantes: ¿cuánto desarrollo endógeno puede generarse en territorios rurales y urbanos impactados por la creciente exogeneidad decisoria en los circuitos y dinámicas agroalimentarias? ¿Cuáles son las políticas e instrumentos con incidencia sobre las dinámicas agro-rurales y urbanas que tienden a profundizar o revertir el actual modelo espacial polarizado?

\section{Dos tópicos del actual debate sobre desarrollo rural}

\section{Del desarrollo agrario al desarrollo territorial rural}

El enfoque del Desarrollo Territorial Rural (DTR) es relativamente novedoso y las políticas encaminadas desde esta perspectiva se apoyan en una amplia y heterogénea discusión académica y política. En una apretada síntesis es posible reconocer la combinación de cuatro aspectos centrales:

El presente texto se basa en el trabajo realizado por los autores para el Área de Desarrollo Rural del Ministerio de Asuntos Agrarios de la Provincia de Buenos Aires, en el marco del PROINDER de la Secretaría de Agricultura, Ganadería Pesca y Alimentos (SAGPyA), citado en la bibliografía. 
- Visión ampliada de lo rural, integrando las otras actividades económicas -además de la agropecuaria- que se desarrollan en este ámbito; "las funciones del espacio rural se amplifican con la incorporación de las relativas al ocio y reserva ambiental" (Gorenstein, 2000, p. 46). Siguiendo la clasificación de la FAO se trata de tres funciones básicas (Piñeiro, 2001, p. 86): la económica (vinculada con las contribuciones que realiza el sector al crecimiento económico global y está principalmente ligada a la producción de bienes comercializables de la producción agropecuaria, agroindustrialización, turismo, etc.); la función ambiental (asociada a la conservación de recursos naturales y a la preservación del medio ambiente); y la función social (vinculada al desarrollo del capital social y al mantenimiento de la vida comunitaria).

- Énfasis en el territorio como la matriz de organización y de interacciones socioeconómicas. Schejtman y Berdegué (2004) señalan: "desde el punto de vista de cada proceso de desarrollo rural en particular, el territorio no es sino el espacio que sus agentes reconocen como necesario (o, al menos, posible) para contener y delimitar las relaciones que establecen entre ellos en el interior, y entre todos y el 'mundo externo', en función de los proyectos u objetivos de desarrollo que se proponen emprender. Puesto de otra forma, el territorio en cada proceso de desarrollo rural es una construcción social, y no un espacio 'objetivamente existente' y delimitable mediante un puro ejercicio técnico ex ante, en virtud de una u otra variable o conjunto de variables físicas o económicas (p. 32).

El PNUD (2002), por su parte, enfatiza en la construcción de capacidades competitivas como elemento clave del proceso de DTR: "el grado de competitividad alcanzado y las posibilidades de modificarlo descansan, además de la capacidad exportadora (y su particular modalidad de inserción internacional) y de atracción de inversiones, en ciertas capacidades básicas relacionadas de una u otra manera con la educación, la relación con el progreso técnico, grupos de activos (o stocks) asocia- dos a la infraestructura (básicamente vial, energética e hídrica) y los recursos naturales (incluyendo las características del ambiente), y la configuración de los tejidos institucionales" (p. 8).

El enfoque del DTR, al igual que en otros campos de las políticas sociales y económicas, postula la necesidad de pasar de un diseño y gestión centralizada a la governance, entendida como un proceso abierto de coordinación económica, social y política entre una multiplicidad de actores e intereses (públicos y privados) que intervienen en territorios rurales. Siguiendo a Cavarozzi (2005): "el DTR resulta de carácter innovador en cuanto a procedimientos o modos de intervención de la autoridad pública, al propiciar la descentralización y fortalecimiento de los gobiernos locales, que entiende como un modo de regulación más sensible a problemáticas altamente heterogéneas, como es la del desarrollo rural; a la vez que señala un también diferente modo de relacionar gobierno y sociedad civil, impulsando la sinergia de ambos sectores mediante procesos de acuerdo y acción conjunta-concertación (p. 9-10).

En suma, este replanteo teórico introduce cambios en los ejes de discusión y en los problemas resaltados en el debate. Como señala Delgadillo Macías (2006), es posible establecer una secuencia temporal de los diferentes enfoques y paradigmas que han orientado a las políticas de desarrollo rural. Desde las primeras intervenciones, centradas en el incremento de la capacidad productiva agraria, pasando, posteriormente, a una línea de marcado carácter sociocultural, se llega a la actualidad, con la adopción de una multiplicidad de enfoques relacionados con la sustentabilidad ambiental y el desarrollo humano-territorial sostenible.

Otra constatación de interés es que el paradigma de DTR se inspira en enfoques desarrollados en el campo de la economía regional e industrial durante las últimas décadas. Comprende contribuciones, muy variadas, sobre gestación y desarrollo de clusters o distritos, regiones de aprendizaje (learning regions) y entornos innovadores (milieu); la línea institucionalista, centrada en el rol de las instituciones públicas y la sociedad civil; y, más en general, el enfoque y modelos de desarrollo endógeno que enfatizan en las dotaciones (natu- 
rales y construidas) ${ }^{2}$. Una heterogénea producción teórica estimulada por las observaciones de un conjunto amplio de estudios de caso, varios de ellos convertidos en tipos ideales de análisis referencial. En este sentido, buena parte de la literatura latinoamericana reciente refleja evidencias bastante distantes a las estilizaciones difundidas desde países desarrollados (principalmente europeos). En general, se trata de aglomeraciones con muy escasas condiciones endógenas relacionadas con el ambiente socioeconómico (medios de producción, insumos, tecnologías, etc.) reducidos a la simple presencia de un conjunto de empresas de un mismo rubro, especie de clusters "truncos" (Schejtman y Berdegué, 2004), de sobrevivencia o en procesos de desclusterización debido a la penetración de las dinámicas globalizadoras (Dirven, 2001).

\section{Neorruralidad}

El concepto de neorruralidad aún se encuentra en construcción; presenta enfoques diversos según el campo disciplinario de observación y los fenómenos o problemáticas que se enfatizan ${ }^{3}$. Desde la sociología rural, por ejemplo, se hace hincapié en las posibilidades de surgimiento de un conjunto social con características complejas y diferentes a las de las sociedades que habitan un medio rural básicamente agropecuario. En el campo de la economía, tal como se reseñó en el acápite anterior, el concepto se vincula con la búsqueda de soluciones globales -no sectoriales- para el desarrollo rural. Por su parte, dentro de la geografía, la noción de neorruralidad suele asociarse a los nuevos procesos y fenómenos que atraviesan las redefiniciones rural-urbanas, abarcando el "desbordamiento de las fronteras metropolitanas". De este modo, las actividades -y los asentamientos- neorrurales formarían parte de las denominadas actividades compensadoras, definidas como aquellas que “...surgen de la necesidad de extensión de la ciudad

\footnotetext{
Para una revisión reciente de estas temáticas, véase, entre otros, a: Campolina (2003); Méndez (2002); Klink (2001); Gorenstein (2005).

El debate acerca de la neorruralidad cobró impulso en la Europa de los años ' 80 apoyado en las políticas de la Unión Europea, particularmente el programa LEADER orientado al desarrollo de áreas rurales atrasadas. Más adelante, la noción pasa a ser utilizada en los ámbitos académicos para identificar actividades a promover dentro del paradigma del desarrollo y la sustentabilidad ambiental.
}

en el campo, así como de las necesidades de sus habitantes, que se buscan satisfacer en el ámbito rural" (García Ramón et al., 1995, p. 59).

Más allá de la diversidad subyacente, estas perspectivas superan la histórica dicotomía analítica de lo rural y lo urbano reconociendo, entre otros procesos, la consolidación de una tendencia demográfica predominantemente urbana, el impacto de este fenómeno sobre la cultura rural (ligada, cada vez más, a expectativas y patrones de vida urbanos), y la incidencia -en un sentido amplio- de las nuevas tecnologías de información y comunicación que mejoran la calidad de las conexiones rural-urbanas.

Los estudios sobre el ámbito rural europeo aluden, habitualmente, a la disolución del límite entre ambos tipos de áreas, hasta que de hecho en muchas circunstancias se transforma en un continuum. Méndez (2006) señala: "el continuo urbano-rural no se entiende tan sólo como una descripción de las consecuencias provocadas por la difusión espacial de la urbanización, sino que justifica una interpretación del territorio, construido por una red de relaciones funcionales, en donde los efectos multiplicadores generados por ciertos núcleos urbanos pueden dinamizar su entorno próximo y servir de soporte -en forma de servicios e infraestructuras- a iniciativas surgidas en las áreas rurales, ayudando así a diversificar sus economías" (p. 9).

La aplicación de la noción de neorruralidad en realidades latinoamericanas tiene un estrecho contacto con las particularidades (sociales, espaciales, económicas) de los territorios analizados. Craviotti (2005, p. 50), revisando algunos estudios recientes, combina tres dimensiones: la diversificación de actividades ligadas a nuevas demandas sociales; la interrelación rural-urbana; y, la existencia de nuevos actores. Manzanal (2006, p. 35), por su parte, refiere a los procesos y dinámicas que no pueden "focalizarse exclusivamente en lo rural" y que se inscriben tanto en los espacios que siguen vinculados a los complejos agroalimentarios, como a los que se han reestructurado y son asiento de actividades turísticas -ambientales; así como los que han entrado en la marginalidad y/o declive económico. 
En este contexto analítico corresponde ubicar el énfasis en la pluriactividad ${ }^{4}$ que surge desde las propuestas de desarrollo rural que se difunden en la región. Con frecuencia, señalan Berdegué et. al. (2001, p. 198), el impulso y crecimiento de las actividades no agrícolas tienen su origen fuera del sector rural una vez que ciertas inversiones (caminos, electrificación) reducen la "distancia económica" que separa al ámbito rural de las fuentes dinámicas de demanda de estos bienes y servicios.

Este tipo de distancia, a su vez, está relacionada con la densidad poblacional. Existe un amplio consenso teórico en torno a las graves dificultades para cualquier proceso de desarrollo, ocasionadas por una configuración de vastos territorios con una densidad demográfica extremadamente baja y una polarización entre pocos núcleos urbanos y el resto. La polarización territorial, expresada en los muy diferentes grados de concentración y crecimiento urbano, constituye un factor importante a la hora de explicar las mayores divergencias sociales en términos de ingresos y acceso a los servicios públicos, así como las pronunciadas diferencias económico-productivas de las estructuras rurales de los países de la región.

Una de las problemáticas asociadas es la distancia entre localidades y ciudades y las deficiencias de infraestructura, sobre todo en las zonas más remotas. Da Silva (1998) sostiene que las falencias en términos de infraestructura social básica y de oportunidades de empleo en actividades no agrícolas convierten a estas localidades en estadios intermedios del proceso de éxodo rural, que termina asentado en las regiones metropolitanas. Está claro, a su vez, que la distancia económica y las limitaciones vinculadas a los diferentes componentes del concepto de proximidad (equipamiento y capital físico; capacidades, saberes y conocimientos; densidad del tejido institucional, etc.) tienen efectos innegables sobre muchas producciones desarrolladas en los poblados rurales. Dirven (2001) señala que estos factores explican el hecho de que

La noción de pluriactividad alude a la diversificación de los ingresos de la familia rural, como resultado de la ocupación de sus miembros en actividades agrícolas y en una amplia gama de actividades no agrícolas. Una visión de esta temática puede verse en Berdegué et al. (2001); Craviotti (2006), entre otros. muchos de los conglomerados agrarios y agroindustriales ubicados en países periféricos, si no la mayoría, sean enclaves o meras aglomeraciones de supervivencia de microempresas.

En suma, la distancia refiere no solo a la lejanía física a los centros urbanos sino también a los consiguientes costos de transacción con los mercados (de trabajo, capital, productos e insumos), a las condiciones de accesibilidad (infraestructuras de comunicación) y a la naturaleza de los encadenamientos locales. Estas ideas se interrelacionan con la temática del empleo e ingresos rurales no agrícolas que hoy se discuten en los estudios sobre el medio rural en el país y América Latina. Asimismo, está explícita o implícita la idea de lo rururbano en tanto espacio de contacto entre el campo y la ciudad donde se intercalan diversas formas de organización territorial, algunas vinculadas con lo urbano y otras con lo rural, y en los cuales tienen más posibilidades de desarrollarse procesos y fenómenos de la neorruralidad (Barros et al., 2005; Manzanal, 2006).

Queda clara, entonces, la importancia que adquiere la configuración de la estructura rural-urbana de un territorio en particular, para favorecer, delimitar y/o perturbar la diversificación de ingresos de la familia rural, como camino de salida de la pobreza rural y, entre otros, como forma de vinculación a mercados externos dinámicos. En lo que sigue se avanza en estos aspectos a partir de evidencias sobre el territorio rururbano bonaerense. Se adopta este criterio desde una visión que alude a la interpenetración de funciones (rural y urbana), conectada con el contexto analítico de la neorruralidad, aunque combinando los factores espaciales (distancia, proximidad en sentido amplio) que contribuyen a la identificación de las condiciones idiosincrásicas de la realidad provincial en cuestión.

\section{Territorios y dinámicas rururbanas bonaerenses}

\section{Regionalización y ruralidad: aspectos metodológicos}

Campo y ciudad no significan lo mismo en todos los lugares; la literatura especializada muestra diversos criterios operacionales que, en rasgos estilizados, pueden agruparse según cuatro enfoques dominantes (García Ramon et al., 1995, 
p. 36-41; Calatrava y Melero, 2003, p. 101-102): i) el administrativo, donde lo rural es definido por el sector público en función de la existencia o no de servicios básicos; ii) el de baja densidad demográfica y de construcciones, centrado entonces en la morfología o distribución del área. El tamaño del núcleo de población es el más utilizado, observándose una fuerte diferenciación entre países y regiones respecto al límite para determinar un carácter rural'; iii) el que privilegia la actividad económica agraria (porcentaje de población activa agraria, relación entre los usos del suelo de tipo agrario y urbano, etc.); iv) centrado en variables cualitativas como la relación de la población con el entorno, arraigo y otros elementos identitarios, por ejemplo, las actitudes o consideraciones sociales que rescatan las diferencias entre el campo y la ciudad (comportamiento electoral, relaciones interpersonales). Estas alternativas pueden, a su vez, combinarse en indicadores múltiples que permiten una explicación más completa del espacio y la sociedad rural.

Los ejes de debate teórico en torno a la ruralidad, señalados en el acápite anterior, también se expresan en nuevas propuestas metodológicas para una mejor aproximación a la visión sobre la integración funcional rural-urbana. En tal sentido, centran la atención en estructuras interconectadas donde las ciudades o aglomeraciones actúan como ejes vertebradores de asentamientos poblacionales de menor tamaño. De este modo, es cada vez más habitual que el territorio se divida en zonas y que se utilice el criterio de densidad poblacional para la distinción entre las áreas rurales y las urbanas ${ }^{6}$.

En Argentina el criterio censal de distinción entre lo rural y lo urbano es de 2.000 habitantes, mientras es de 300 en Dinamarca, por ejemplo, o de 30.000 en Japón.

6 La OCDE (1994) distingue entre dos niveles jerárquicos de unidades territoriales: a nivel de la comunidad local, son rurales aquellas con una densidad menor a los 150 hab./km2; a nivel regional, diferenciando entre tres tipos según población, las predominantemente rurales (más de un $50 \%$ de la población vive en comunidades rurales), significativamente rurales (entre el 15 y el $50 \%$ de la población vive en comunidades rurales) y predominantemente urbanas (menos del $15 \%$ de la población vive en comunidades rurales). La Unión Europea, por su parte, ajusta en 100 hab. / km2 el umbral de densidad de población de las comunidades rurales (Calatrava y Melero, 2003).
En el presente estudio se ha intentado una aproximación a los criterios contemporáneos de ruralidad, teniendo en cuenta la particular configuración territorial de la provincia de Buenos Aires. En efecto, dada la histórica segmentación entre la Región Metropolitana y el Interior provincial, se ha definido el umbral de $16,73 \mathrm{hab}$. $/ \mathrm{km} 2$ para diferenciar entre los partidos rurales y los urbanos. El cálculo de densidad poblacional contempla un total de 109 partidos, considerando que entre los habitantes de los partidos que integran el tercer cordón metropolitano bonaerense, así como de aquellos donde se ubican las ciudades más importantes de la provincia (Ver Figura 1), hay un conjunto significativo relacionado a la actividad agropecuaria y rural en general.

Teniendo en cuenta lo anterior, se tipifica como:

- predominantemente rurales: a las áreas donde el $50 \%$ o más de la población vive en partidos considerados rurales;

- $\quad$ significativamente rurales: si la proporción de la población que vive en partidos rurales está entre el $15 \%$ y $50 \%$;

predominantemente urbana: menos del 15\% de su población vive en partidos rurales.

Esta caracterización se aplica a la regionalización utilizada habitualmente por organismos oficiales, que divide a la provincia en ocho zonas agro-productivas: ${ }^{7}$ zona núcleo agrícola del norte (ZNAgN); Zona Mixta del Noroeste (ZMxNO); Zona Mixta del Centro (ZMxC); Zona Noreste (ZNE); Zona Ganadera de la Cuenca del Salado (ZGCS); Zona mixta del Centrosur (ZMCS); Zona Mixta del Suroeste(ZMSO); Zona de riego y ganadera árida del Sur (RGASur). (Ver Figura 2). De este modo, se intenta una aproximación a la intensidad del proceso (ruralidad-urbanización).

Combina dos criterios: i) geográfico: agrupa a los partidos en grandes unidades (norte, centro, sudoeste, etc.) y ciertas características ecológicas (cuenca del Salado, árida y de riego del sur); agro-productivo: producción dominante, delimitando dichas unidades geográficas según predominio agrícola, ganadero o ambas. 
Figura 1. Mapa de la Provincia de Buenos Aires. Partidos clasificados según cantidad de habitantes

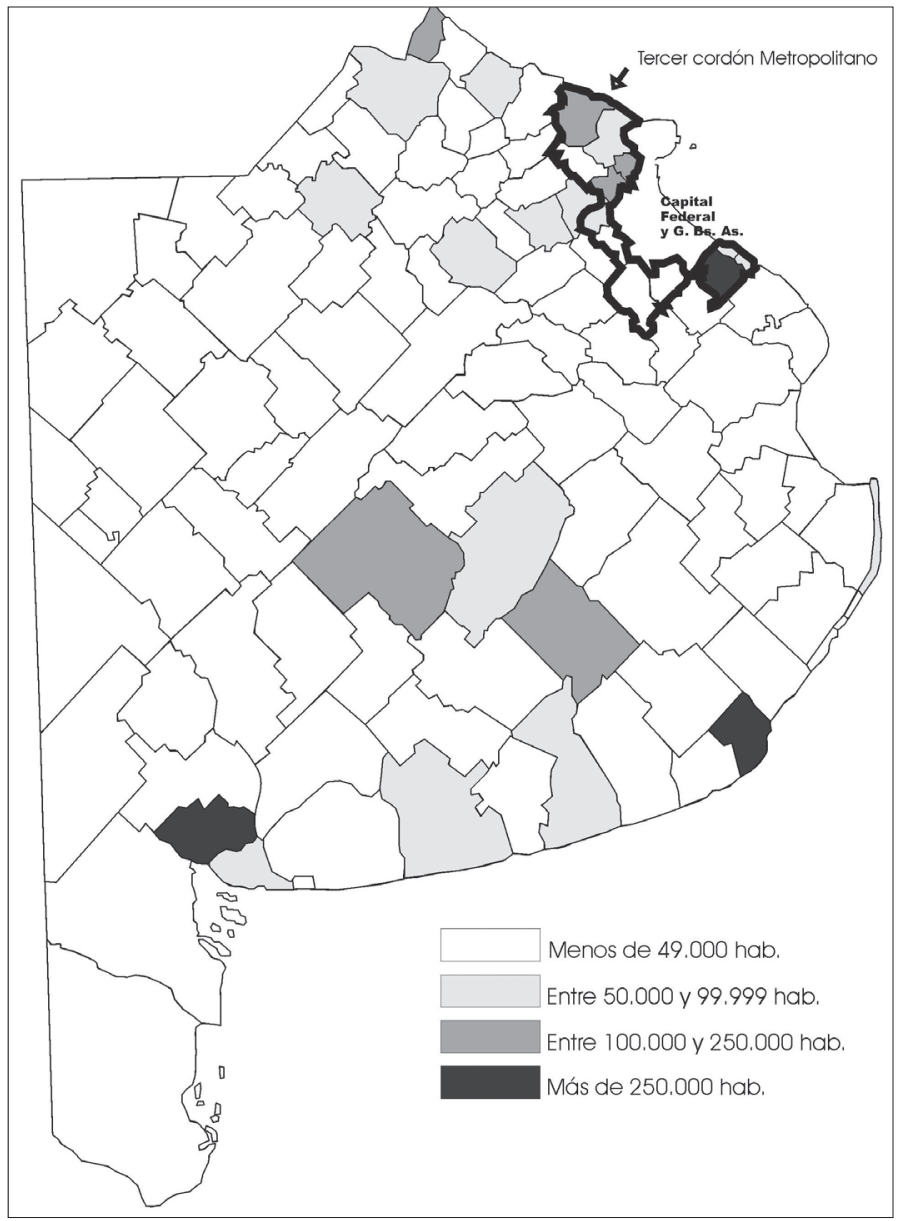

Fuente. Elaboración propia

\section{Tendencias demográficas}

Históricamente, el interior bonaerense -al igual que el conjunto del espacio productivo pampeano- se ha caracterizado por un elevado índice de urbanización derivado, entre otros factores, de los rasgos tecno-productivos que sustentaron la trayectoria de la actividad agropecuaria desde la etapa agroexportadora. Desde esta fase se fue cristalizando un ámbito espacial organizado en forma jerárquica según el alcance y complejidad de las interconexiones rural-urbanas: junto a los centros de mayor tamaño, un grupo de pequeños y medianos poblados fueron integrando la estructura urbana del interior provincial (Gorenstein, 2000). Entre 1947-1960, la participación en el total de la población rural bonaerense desciende del $29 \%$ al
13\%, alcanzando sólo un 9\% en la década del 70 . En este período, el proceso de urbanización de la población provincial supera al que se produce en el total del país, reflejando los efectos de la corriente migratoria atraída por el desarrollo de actividades manufactureras localizadas en la porción bonaerense del área metropolitana.

Diferentes dinámicas en la agricultura impulsan la urbanización de la población rural bonaerense. Un proceso de rururbanización típicamente pampeano, donde una alta proporción de productores reside en la ciudad cabecera o más importante del distrito (partido o departamento, según provincia). La fase de modernización del agro pampeano más reciente, motoriza otras transformaciones estructu- 
Figura 2. Zonas agroproductivas y grados de ruralidad

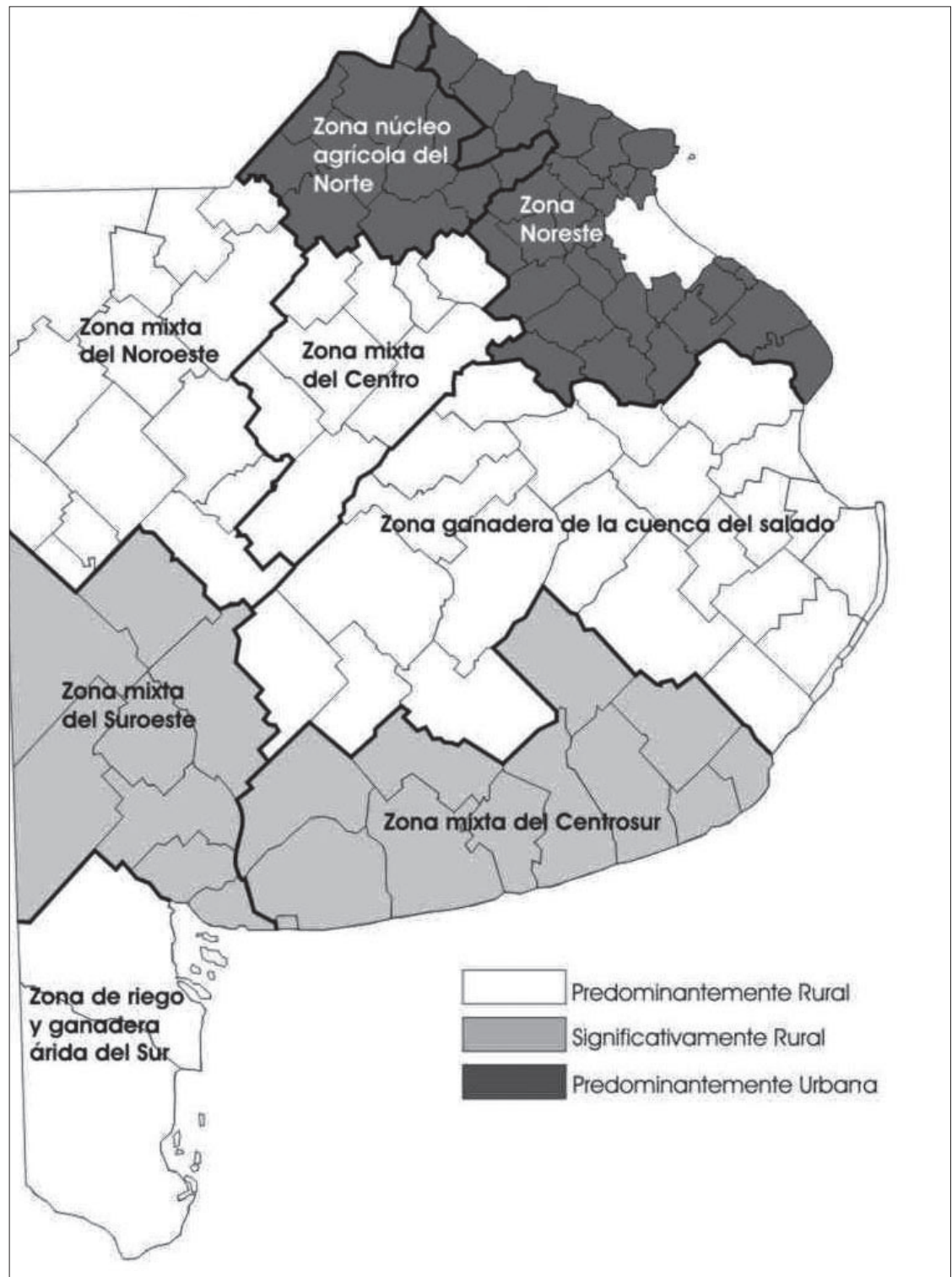

Fuente. Elaboración propia

rales que alteran las características de la migración rural bonaerense. Por un lado, las nuevas formas organizacionales que se difunden en el agro (pool de siembra, consorcios de inversiones), sumado a las mayores exigencias en términos de tamaño y escala económica de las explotaciones, complejiza la evolución y posibilidades de inserción de los pequeños y medianos productores familiares. En este sentido la información del Cuadro 1 es muy ilustrativa: el trabajo permanente en las explotacio- nes agropecuarias (EAPs) desciende un 33\% en el período 1988-2002, considerando el realizado por los productores y familiares así como del personal asalariado.

La dinámica demográfica no ha sido uniforme entre las regiones y los partidos que las integran; siguiendo los criterios ya comentados, el resultado entre los dos últimos censos va asociado a un conjunto de datos interesantes (Ver Cuadros 2 y 3): 
Territorios agrarios y realidades rururbanas. Reflexiones sobre el desarrollo rural a partir del caso pampeano bonaerense

Cuadro 1. Provincia de Buenos Aires. Empleo Rural Permanente en EAPs. 1988 - 2002

\begin{tabular}{|l|c|c|c|}
\hline Relación con el productor & $\mathbf{1 9 8 8}$ & $\mathbf{2 0 0 2}$ & Variación (\%) \\
\hline Productor & 68.673 & 54.184 & -21 \\
\hline Familiares del productor & 27.212 & 12.343 & -55 \\
\hline No familiares del productor & 85.794 & 54.936 & -36 \\
\hline Total & 181.679 & 121.463 & -33 \\
\hline
\end{tabular}

Fuente. CNA 1988 y 2002, en base a información Dirección de Estadística de la Provincia de Buenos Aires

Cuadro 2. Provincia de Buenos Aires: evolución de la población en partidos rurales y urbanos. Dinámica poblacional de partidos rurales, 1991-2001.

\begin{tabular}{|c|c|c|c|c|c|c|c|}
\hline \multirow[b]{2}{*}{ Tipo } & \multirow{2}{*}{$\begin{array}{l}\text { D inám ica } \\
\text { poblacional }\end{array}$} & \multicolumn{2}{|c|}{ Partidos } & \multicolumn{2}{|c|}{ Población } & \multirow{2}{*}{$\begin{array}{c}\text { Variación } \\
\text { 1991-2001 } \\
\text { (en hab.) }\end{array}$} & \multirow{2}{*}{$\begin{array}{c}\text { Variación } \\
1991-2001 \\
(\text { en \%) }\end{array}$} \\
\hline & & No & $\begin{array}{c}\text { \% pob. } \\
2001\end{array}$ & 1991 & 2001 & & \\
\hline \multirow[t]{4}{*}{ Rurales } & Expulsan & 18 & 26,9 & 261.263 & 250.399 & -10.864 & $-4,2$ \\
\hline & Mantienen & 35 & 52,2 & 892.645 & 907.077 & 14.432 & 1,6 \\
\hline & Atraen & 14 & 20,9 & 178.709 & 205.503 & 26.794 & 15 \\
\hline & Total & 67 & 100 & 1.332 .617 & 1.362 .979 & 30.362 & 2,3 \\
\hline Urbanos & & 42 & & 3.268 .434 & 3.719 .596 & 451.162 & 13,8 \\
\hline
\end{tabular}

Fuente. Elaboración propia en base a información de INDEC, CNP 1991; 2001.

La población de los 67 partidos rurales superaba el millón trescientos mil habitantes en el último registro censal, un $27 \%$ de la población de las ocho zonas agro-productivas consideradas y un $10 \%$ del total de la provincia. Más de tres millones y medio de personas se distribuyen en los 42 partidos urbanos, una magnitud que se reduce sustantivamente (casi 1.600.000 habitantes) si se deja de lado el tercer cordón metropolitano, la unidad territorial más urbanizada de la provincia. Esta zona -el Noreste- gana representación en el agregado provincial (del 36 al 39\% entre 1991-2001) mientras que la Cuenca del Salado manifiesta una leve subida.

- $\quad$ Entre los distritos rurales, 18 son expulsores, otros 35 mantienen y 14 han ganado población en el período. Esto significa un aumento de un poco más de 30.000 personas habitando en el medio rural, que contrasta con casi el medio millón de crecimiento en el volumen censado dentro de los ámbitos urbanos. Excepto dos casos (Carmen de Areco y Trenque Lauquén) los partidos rurales que han atraído población se ubican en la
Cuenca del Salado y el Noreste, agregados regionales con tasas de crecimiento poblacional superiores a la del conjunto provincial $(10,4 \%)$. En cambio, en las Mixtas del Centro y Suroeste se ubica la mayoría de los partidos que pierden habitantes.

Los centros que más crecen son las cabeceras de partidos o los de mayor jerarquía urbana, los ubicados en las proximidades del cordón metropolitano bonaerense, y los que delimitan los municipios costeros. En tal sentido, resulta ilustrativa la tasa de crecimiento de Pinamar, Gesell y las dos localidades del Municipio de la Costa (Mar de Ajó y San Bernardo) que explican más del 30\% del incremento poblacional registrado en la cuenca del Salado, así como los casos de Pilar y Escobar que en conjunto representan casi el $41 \%$ de la suba absoluta de población experimentada por la zona noreste. En general, el peso de la población asentada en las cabeceras de partido ha 
Cuadro 3. Provincia de Buenos Aires: población en zonas agroproductivas. Dinámica poblacional de los partidos que las componen, 1991-2001.

\begin{tabular}{|c|c|c|c|c|c|c|}
\hline ZONA & $\begin{array}{l}\text { Partidos que } \\
\text { la conforman }\end{array}$ & $\begin{array}{l}\text { \% de la } \\
\text { población } \\
\text { provincial } \\
\text { en } 1991\end{array}$ & $\begin{array}{l}\% \text { de la } \\
\text { población } \\
\text { provincial } \\
\text { en } 2001\end{array}$ & $\begin{array}{l}\text { Partidos } \\
\text { ganadores }\end{array}$ & $\begin{array}{c}\text { Partidos } \\
\text { perdedores }\end{array}$ & $\begin{array}{c}\text { Variación } \\
\text { población } \\
(\%)\end{array}$ \\
\hline Mixta del Centro & 8 & 5,6 & 5,18 & 0 & 4 & 2,3 \\
\hline Mixta del Sur Oeste & 8 & 9,68 & 9,01 & 0 & 3 & 2,8 \\
\hline Mixta del Noroeste & 14 & 5,43 & 5,08 & 1 & 5 & 3,3 \\
\hline Mixta del Centro Sur & 12 & 20,22 & 19,24 & 2 & 4 & 5,1 \\
\hline $\begin{array}{l}\text { Núcleo Agrícola del } \\
\text { Norte }\end{array}$ & 11 & 10,83 & 10,31 & 3 & 1 & 5,1 \\
\hline $\begin{array}{l}\text { Ganadera de la } \\
\text { Cuenca del Salado }\end{array}$ & 25 & 10,78 & 11,08 & 10 & 2 & 13,5 \\
\hline Noreste & 29 & 36,33 & 39,02 & 21 & 0 & 18,7 \\
\hline $\begin{array}{l}\text { De Riego y Ganadera } \\
\text { Árida del Sur }\end{array}$ & 2 & 1,13 & 1,07 & 0 & 0 & 4,9 \\
\hline
\end{tabular}

Fuente. Elaboración propia en base a información de INDEC. CNP 1991; 2001.

seguido aumentando, ${ }^{8}$ si bien se presentan casos como el sur de la provincia (zona de riego y ganadera árida del sur) donde las localidades ubicadas en la cuenca de riego de la Corporación de Fomento del Río Colorado (CORFO) han crecido mucho más que las respectivas capitales de distrito (Médanos en Villarino y Carmen de Patagones en el partido del mismo nombre).

\section{Reconfiguración rural-urbana}

Al igual que el crecimiento demográfico, el proceso de urbanización ocurrió con una fuerte diferenciación entre las regiones consideradas. En primer lugar, condensando regionalmente esta información según el corte urbano-rural adoptado, el grado de la urbanización provincial se redimensiona. En efecto, sólo las regiones núcleo del norte y la del noreste pueden considerarse urbanizadas, con centros de porte medio y no metropolitanos que han seguido creciendo durante la última dé-

8 Berger (2003) presenta evidencias sobre el comportamiento de los productores agropecuarios asentados en un partido próximo al ámbito metropolitano. Entre los titulares de EAPs del partido de Cañuelas, por ejemplo, un poco más del $40 \%$ reside en Capital/GBA, en tanto que el 18,3\% reside en el establecimiento (en áreas rurales) y un 38,3\% reside mayoritariamente en la ciudad de Cañuelas y en escasa medida en localidades de otros partidos cercanos. cada. Las restantes regiones, en cambio, muestran el predominio de la ruralidad con intensidades distintas (Ver Cuadro 4 y Figura 2).

En segundo lugar, la visión de la distribución territorial de la población en los 109 partidos es bastante expresiva del patrón de urbanización y la forma en que se organizan los sistemas urbanoregionales en el llamado interior de la provincia (Ver Cuadros 5 y 6):

En el extremo sur, la zona de riego y ganadera (partidos de Villarino y Patagones), con apenas el $1 \%$ de la población provincial, mayoritariamente aglomerada en localidades menores a los 10.000 habitantes; en cambio, en el NE sólo un $8 \%$ de su población se distribuye en localidades de este tamaño. Así, en esta región más de la mitad de sus habitantes se concentran en tres ciudades (La Plata, Pilar y Zárate) con una población superior a los 100.000 habitantes, y los restantes se distribuyen en centros como Campana, Berisso, Ensenada, San Pedro y Zárate, y un conjunto de ciudades entre 10.000 y menos de 50.000. El rasgo de concentración geográfica de la población en ciudades de más de 100.000 habitantes también se manifiesta en la zona mixta del centrosur, donde alrededor de la mitad de 
Territorios agrarios y realidades rururbanas. Reflexiones sobre el desarrollo rural a partir del caso pampeano bonaerense

Cuadro 4. Provincia de Buenos Aires: grado de ruralización en zonas agroproductivas.

\begin{tabular}{|l|c|l|}
\hline \multicolumn{1}{|c|}{ Zona } & \% Población en partidos rurales & \multicolumn{1}{c|}{ Tipo de Región } \\
\hline Ganadera de la Cuenca del Salado & 81,3 & Predominantemente Rural \\
\hline Mixta del Centro & 61,7 & Predominantemente Rural \\
\hline Mixta del Centro Sur & 18,1 & Significativamente Rural \\
\hline Mixta del Noroeste & 100 & Predominantemente Rural \\
\hline Mixta del Sur Oeste & 24,5 & Significativamente Rural \\
\hline Núcleo Agrícola del Norte & 9,9 & Predominantemente Urbana \\
\hline Noreste & 4,5 & Predominantemente Urbana \\
\hline De Riego y Ganadera Árida del Sur & 100 & Predominantemente Rural \\
\hline
\end{tabular}

Fuente. Elaboración propia en base a información de INDEC-CNP, 2001.

su población se aglomera en las capitales de los partidos de Gral Pueyrredón y Tandil, y la del sudoeste (Bahía Blanca).

En la Cuenca del Salado, sólo dos ciudades superan los 50.000 habitantes: Olavarría y Azul, ambas junto a las 14 localidades del estrato inferior absorben un 78\% de la población; el resto de los habitantes se distribuye en 70 aglomeraciones menores a los 10.000. De forma similar, en la zona mixta del noroeste se ubica una malla de 72 localidades menores a los 10.000; mientras que aquí se concentran casi la mitad de sus habitantes los restantes lo hacen en 6 centros que superan los 10.000 habitantes pero llegando sólo en el caso de Trenque Lauquén a los 30.000. Cabe hacer notar, en este caso, otro fenómeno ilustrativo: la población asentada en pequeños centros (entre 2.0009.999 habitantes) disminuyó, por el cambio de intervalo de las cabeceras de partido como Daireux y América, mientras que la cantidad de habitantes de las localidades rurales prácticamente se mantiene en el período considerado. En la zona mixta del centro, las localidades menores a los 10.000 habitantes concentran un $9 \%$ del total de la región, y es en los centros entre este piso y menos de 100.000 habitantes donde se aglomera más del $80 \%$ de los habitantes. Al igual que en el caso de la GCS, se produce un aumento en la jerarquía urbana de la región por el paso de la ciudad cabecera de Chivilcoy al rango que supera los 50.000 habitantes.
Por último, los datos desagregados por partido reafirman la urbanización de la zona núcleo agrícola del norte, la de mayor densidad (casi 30 habitantes por $\mathrm{km}^{2}$ ) fuera de la unidad territorial integrada por partidos del cordón metropolitano (zona noreste). Una sola ciudad -cabecera de partido- que supera los 100.000 habitantes (San Nicolás de los Arroyos), con algo más del $25 \%$ de la población regional, y una red de nueve centros pequeños y medianos, también cabeceras de partido, con una población superior a los 10.000 y menos de 100.000 , donde se localiza más del 64\% de la misma. Adicionalmente, las localidades ubicadas en los dos estratos inferiores pierden participación entre los dos censos.

Las evidencias anteriores sugieren el mantenimiento de un movimiento natural positivo de la mayor parte de los centros medianos, dentro del área no metropolitana. El crecimiento demográfico, conjugado con el proceso de urbanización, implicó el aumento de la red urbana de ciudades con una población superior a los 10.000 habitantes, de 69 en 1991 a 76 en 2001, con 21 que superan los 50.000 habitantes. Esto significa, básicamente, que los pequeños pueblos dispersos y localizados en la zona de influencia siguen siendo un estadio intermedio para las migraciones en dirección a los centros mayores.

Una segunda cuestión es la configuración espacial de estas ciudades con sus respectivas subregiones. Aquí cabe seguir pensando en términos de "urbanización polarizada", esto es: 
Cuadro 5. Provincia de Buenos Aires. Población de las zonas agroproductivas por tamaño de localidad. Participación sobre población total de la zona, 1991-2001.

\begin{tabular}{|l|r|r|r|r|r|r|}
\hline & \multicolumn{2}{|c|}{$\begin{array}{c}\text { Ganadera de la } \\
\text { Cuenca del Salado }\end{array}$} & \multicolumn{2}{c|}{ Mixta del Centro } & \multicolumn{3}{c|}{ Mixta del Centro Sur } \\
\hline Intervalo de población (habitantes) & 1991 & 2001 & 1991 & 2001 & 1991 & 2001 \\
\hline 0 -1999 & 4,1 & 3,6 & 11 & 9,4 & 2,4 & 3,2 \\
\hline $2000-9999$ & 19,6 & 18 & 8,1 & 8,7 & 4,5 & 4,4 \\
\hline $10000-49999$ & 58,7 & 52,2 & 80,8 & 59,9 & 15,7 & 15,9 \\
\hline $50000-99999$ & 17,6 & 26,3 & 0 & 22 & 18,8 & 8,5 \\
\hline $100.000-249999$ & 0 & 0 & 0 & 0 & 0 & 10,7 \\
\hline Más de 250.000 & 0 & 0 & 0 & 0 & 58,6 & 57,4 \\
\hline & 100 & 100 & 100 & 100 & 100 & 100 \\
\hline
\end{tabular}

\begin{tabular}{|l|c|c|c|c|c|c|}
\hline & \multicolumn{2}{|c|}{ Mixta del Noroeste } & Mixta del Sur Oeste & \multicolumn{3}{c|}{ Noreste } \\
\hline Intervalo de población (habitantes) & 1991 & 2001 & 1991 & 2001 & 1991 & 2001 \\
\hline 0-1999 & 16 & 15,2 & 4,3 & 4,9 & 2,2 & 2,1 \\
\hline 2000-9999 & 40,5 & 30,8 & 12,6 & 11,8 & 6,2 & 5,7 \\
\hline $10000-49999$ & 43,6 & 54 & 7,9 & 8,2 & 22,6 & 15,5 \\
\hline $50000-99999$ & 0 & 0 & 13,4 & 13 & 18,2 & 25,4 \\
\hline $100.000-249999$ & 0 & 0 & 0 & 0 & 16,9 & 21,2 \\
\hline Más de 250.000 & 0 & 0 & 61,8 & 62 & 34,1 & 30 \\
\hline & 100 & 100 & 100 & 100 & 100 & 100 \\
\hline
\end{tabular}

\begin{tabular}{|l|c|c|c|c|}
\hline & \multicolumn{2}{|c|}{ Núcleo Agrícola del Norte } & \multicolumn{2}{|c|}{ De Riego y Ganadera Árida del Sur } \\
\hline Intervalo de población (habitantes) & 1991 & 2001 & 1991 & 2001 \\
\hline 0 -1999 & 6 & 5,7 & 16,9 & 11,3 \\
\hline $2000-9999$ & 7,1 & 4,6 & 39,3 & 49,2 \\
\hline $10000-49999$ & 26,9 & 30,8 & 43,9 & 39,6 \\
\hline $50000-99999$ & 33,8 & 33,8 & 0 & 0 \\
\hline $100.000-249999$ & 26,1 & 25,2 & 0 & 0 \\
\hline Más de 250.000 & 0 & 0 & 0 & 100 \\
\hline
\end{tabular}

Fuente. Elaboración propia en base a información de INDEC-CNP 1991; 2001.

unos pocos centros urbanos de medio o gran porte distantes entre sí, donde se dan relaciones verticales, jerárquicas, entre cada centro y su hinterland. Este patrón surge básicamente de dos factores: por un lado, la existencia de un grupo discontinuo de poblados, cuyo tamaño no justifica la producción local de ciertos bienes, articulados en forma jerárquica a lo largo de las redes camineras y los corredores ferroviarios (en general, desactivados). Por otro lado, la extensión geográfica del territorio regional y el desarrollo de las aglomeraciones secundarias que, sostenidas en primer lugar por su propio crecimiento demográfico, se han tornado en oferentes de estos pequeños pueblos. 
Cuadro 6. Provincia de Buenos Aires. Cantidad de localidades por zona agroproductiva. Clasificación según tamaño, 1991-2001.

\begin{tabular}{|l|c|c|c|c|c|c|}
\hline & \multicolumn{2}{|c|}{$\begin{array}{c}\text { Ganadera de la } \\
\text { Cuenca del Salado }\end{array}$} & \multicolumn{2}{c|}{ Mixta del Centro } & \multicolumn{3}{c|}{ Mixta del Centro Sur } \\
\hline Intervalo de población (habitantes) & 1991 & 2001 & 1991 & 2001 & 1991 & 2001 \\
\hline $0-1999$ & 44 & 51 & 54 & 55 & 52 & 56 \\
\hline $2000-9999$ & 18 & 19 & 5 & 6 & 9 & 7 \\
\hline $10000-49999$ & 14 & 14 & 7 & 6 & 6 & 6 \\
\hline $50000-99999$ & 1 & 2 & 0 & 1 & 2 & 1 \\
\hline $100.000-249999$ & 0 & 0 & 0 & 0 & 0 & 1 \\
\hline Más de 250.000 & 0 & 0 & 0 & 0 & 1 & 1 \\
\hline Total Localidades & 77 & 86 & 66 & 68 & 70 & 72 \\
\hline
\end{tabular}

\begin{tabular}{|l|c|c|c|c|c|c|}
\hline & \multicolumn{2}{|c|}{ Mixta del Noroeste } & Mixta del Sur Oeste & \multicolumn{3}{c|}{ Noreste } \\
\hline Intervalo de población (habitantes) & 1991 & 2001 & 1991 & 2001 & 1991 & 2001 \\
\hline $0-1999$ & 56 & 58 & 39 & 42 & 70 & 86 \\
\hline $2000-9999$ & 16 & 14 & 13 & 12 & 17 & 19 \\
\hline $10000-49999$ & 4 & 6 & 2 & 2 & 13 & 13 \\
\hline $50000-99999$ & 0 & 0 & 1 & 1 & 4 & 7 \\
\hline $100.000-249999$ & 0 & 0 & 0 & 0 & 2 & 2 \\
\hline Más de 250.000 & 0 & 0 & 1 & 1 & 1 & 1 \\
\hline Total Localidades & 76 & 78 & 56 & 58 & 107 & 128 \\
\hline
\end{tabular}

\begin{tabular}{|l|c|c|c|c|}
\hline & \multicolumn{2}{|c|}{ Núcleo Agrícola del Norte } & \multicolumn{2}{c|}{ De Riego y Ganadera Árida del Sur } \\
\hline Intervalo de población (habitantes) & 1991 & 2001 & 1991 & 2001 \\
\hline $0-1999$ & 47 & 50 & 10 & 9 \\
\hline $2000-9999$ & 8 & 7 & 4 & 5 \\
\hline $10000-49999$ & 6 & 7 & 1 & 1 \\
\hline $50000-99999$ & 2 & 2 & 0 & 0 \\
\hline $100.000-249999$ & 1 & 1 & 0 & 0 \\
\hline Más de 250.000 & 0 & 0 & 0 & 15 \\
\hline Total Localidades & 64 & 67 & 15 & 0 \\
\hline
\end{tabular}

Fuente. Elaboración propia en base a información de INDEC-CNP 1991; 2001.

Estas tendencias, sin embargo, no provocan inflexiones a la trayectoria anterior en la provincia: i) una urbanización con pocos centros intermedios, entre el gran aglomerado metropolitano-bonaerense y los centros posicionados en una dimensión mayor a los 100.000 habitantes; ii) crecimiento urbano por succión del espacio rural envolvente. En este contexto, se plantean limitaciones en las accesibilidades locales-regio- nales y conexiones interurbanas derivadas de la insuficiente articulación del sistema de transporte y sus excesivos costos.

\section{Los territorios de la pluriactividad}

El tema de la pluriactividad en el agro pampeano se ha convertido en un eje importante de estudios recientes (Neiman y Craviotti, 2005). Aun cuando se reconoce una menor difusión en 
relación a otras regiones del país, su presencia entre las estrategias y senderos evolutivos de los pequeños y medianos productores familiares indicaría que el fenómeno trasciende a los sectores pobres. Tort y Román (2005) sistematizan contribuciones recientes en esta línea y señalan que: "la multiocupación o pluriactividad es elegida, en muchos casos, como la vía de superación a la crisis de este tipo de productores, (mientras que) para otros se constituye en la vía de ingreso a la actividad (agropecuaria) (...) Mientras el empleo asalariado aparece entre los productores pluriactivos como el más frecuente en regiones de características más campesinas como el NOA y NEA, el cuentapropismo predomina en las provincias que conforman la región pampeana" (p. 52-53).

Las posibilidades y dimensión de los ingresos extraprediales o de ingresos no agrícolas para la población rural están también asociadas a la variedad de situaciones o de configuraciones territoriales. Por un lado, no puede desconocerse la influencia que ejerce el entorno económico urbano-regional en relación a la demanda de bienes y servicios del medio rural, así como ámbito donde se concentran diversos mercados de trabajo. Por otro lado, existen distintos tipos de territorios, zonas, centros, etc. y vinculaciones con la base agropecuaria. En la literatura se encuentran varias tipologías. Schejtman y Berdegué (2004) refieren a la realizada por Da Veiga (2001) que se basa en el dinamismo relativo del territorio combinado con la estructura agraria; Berdegué et al. (2001), asocian el desarrollo del empleo rural no agrícola (ERNA) con la existencia de fuentes de demanda (motores endógenos y exógenos) asentadas en la propia actividad primaria, sus encadenamientos, y en aquella derivada de la población y expansión urbana.

En el presente estudio se ha trabajado con una tipología territorial combinando tres elementos: i) las funciones urbanas relacionadas con el entorno rural y, específicamente, la actividad agraria; ii) grado relativo de diversificación de la estructura productiva $y$, por lo tanto, la apertura en relación a las oportunidades de trabajo o ingreso no agrícola tanto rural como urbano; iii) presencia regional de actividades agrícolas intensivas. En base a estos criterios se han identificado tres tipos de situaciones:
Territorios rurales donde se combina la dinámica de centros logísticos. En un sentido amplio abarcan desde las funciones portuarias para los complejos agro-exportadores tradicionales (cereales, oleaginosos, carne) pasando por las administrativogubernamentales relacionadas con estos $\mathrm{u}$ otros complejos agroalimentarios, hasta las vinculadas al comercio y otros servicios. Poseen una fuerte institucionalidad públicoprivada relacionada con estas producciones; además, son los ámbitos desde donde se proveen los servicios más complejos (asesoramiento tecnológico, provisión de algunos insumos, sistemas de información y comercialización, etc.), y en los cuales suelen reciclarse ciertos ingresos del sector primario (inversiones inmobiliarias, flujos financieros, bienes de consumo, etc.). Las industrias agroalimentarias poseen un peso importante y dentro de ellas, se distinguen las empresas medianas-grandes que operan en mercados extra-regionales (nacionales e internacionales). Como su estructura productiva es más diversificada, habitualmente atraen los flujos migratorios rurales o de otros poblados y centros regionales menores, que buscan trabajo, educación, etc. Además de las ciudades-puerto de Bahía Blanca y Necochea, puede ubicarse en este grupo a las dos ciudades de mayor importancia en la provincia (La Plata y Mar del Plata), integrando las regiones $\mathrm{MxSO}$, MxCS y $\mathrm{NE}$. En el cordón metropolitano bonaerense como en las distintas ciudades del interior funcionan los denominados cinturones verdes, integrados por una trama de quintas o huertas familiares $-\mathrm{y}$ otras de características más empresariales-, cuya producción se destina especialmente a verduras de hoja y hortalizas de estación.

Territorios rurales donde se combinan dinámicas de centros neo-rurales. Su rasgo distintivo es la descentralización residencial y otras actividades de "compensación urbana", en especial las vinculadas con servicios de ocio y turismo. Así, desde los barrios cerrados y countries a los nuevos emprendimientos ligados a proyectos agro-productivos 
Cuadro 7. Provincia de Buenos Aires. Situación Territorial según potencialidad para el empleo rural no agrícola (ERNA).

\begin{tabular}{|c|c|c|c|c|c|}
\hline \multicolumn{2}{|c|}{ Centros } & Fuentes o motores & Potencialidad & Ejemplos & Zonas Agroprod. \\
\hline \multirow[b]{3}{*}{ 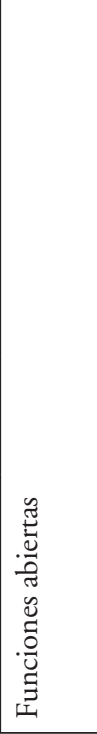 } & \multirow[b]{2}{*}{ Logísticos } & $\begin{array}{l}\text { ERNA por vínculos } \\
\text { hacia delante comple- } \\
\text { jos agro-exportadores } \\
\text { y otros agroalimen- } \\
\text { tarios }\end{array}$ & & $\begin{array}{l}\text { Servicios a la produc- } \\
\text { ción (asesoramiento } \\
\text { tecnológico, provisión } \\
\text { de insumos, comercia- } \\
\text { lización; portuarias) } \\
\text { Agroindustrias }\end{array}$ & MxSO y MxCS \\
\hline & & $\begin{array}{l}\text { Mercado de trabajo } \\
\text { ERNA vinculado } \\
\text { demanda diversificada } \\
\text { de bienes y servicios } \\
\text { población urbana }\end{array}$ & Alta & \multirow[b]{2}{*}{$\begin{array}{l}\text { Turismo } \\
\text { Servicios en casas de } \\
\text { fin de semana (jardi- } \\
\text { nería, limpieza...) } \\
\text { Construcción } \\
\text { Comercio-Servicios }\end{array}$} & \multirow[b]{2}{*}{$\begin{array}{l}\text { GCSal (partidos cos- } \\
\text { teros); NE y NAgN }\end{array}$} \\
\hline & $\begin{array}{l}\text { Neo- } \\
\text { rurales }\end{array}$ & $\begin{array}{l}\text { ERNA asociado } \\
\text { al consumo de la } \\
\text { población urbana } \\
\text { y a la expansión } \\
\text { metropolitana }\end{array}$ & Alta & & \\
\hline \multirow[b]{2}{*}{ 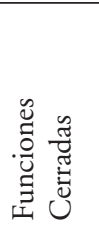 } & $\begin{array}{l}\text { Agro } \\
\text { ciudades }\end{array}$ & \multirow{2}{*}{$\begin{array}{l}\text { ERNA por vínculos } \\
\text { de producción con } \\
\text { actividades agrope- } \\
\text { cuarias y agroalimen- } \\
\text { tarias }\end{array}$} & \multirow[b]{2}{*}{$\begin{array}{l}\text { Medio-Bajo o } \\
\text { muy bajo según } \\
\text { los casos }\end{array}$} & \multirow{2}{*}{$\begin{array}{l}\text { Contratistas de } \\
\text { maquinaria } \\
\text { Agro-servicios } \\
\text { Transportistas } \\
\text { Agroindustrias } \\
\text { Empleo público }\end{array}$} & \multirow[b]{2}{*}{$\begin{array}{l}\text { MxNO, MxC y } \\
\text { RGASur. }\end{array}$} \\
\hline & $\begin{array}{l}\text { Centros } \\
\text { para-agra- } \\
\text { rios }\end{array}$ & & & & \\
\hline
\end{tabular}

Fuente. Elaboración propia a partir de Berdegué et. al. (2001).

(en general, de la mano de emprendedores urbanos), pasando por las instalaciones dedicadas total o parcialmente al turismo rural en diferentes variantes (de estancia, granjas educativas, visitas gastronómicas, etc.), se derivan demandas de bienes y servicios en cuya producción pueden intervenir habitantes del medio rural. Por su parte, la agricultura se destaca por el desarrollo de actividades intensivas como los cultivos bajo invernáculo, la floricultura u otras producciones de este tipo que constituyen otra fuente de empleo. Numerosos centros de la región NE como Pilar, Escobar, Luján, Tigre, Gral. Rodríguez, Cañuelas, entre los más importantes, son buenos ejemplos en este sentido (Barros et al., 2005). Pero, además, cabe contemplar en este marco a los centros costeros de la ZGCSal que en los últimos años han experimentado un creci- miento poblacional y un flujo de inversiones en el sector turismo.

Territorios rurales donde se combinan dinámicas de agrociudades, y centros paraagrarios. Se distinguen por tener una base económica significativamente asociada al sector agropecuario y, más en general, agroalimentario. Naturalmente, ambos conjuntos difieren en dimensión y alcance de las cadenas de valor ligadas al agro regional. En las primeras, se localizan importantes estructuras de acopio y comercialización de granos, mercados de hacienda, algunos frigoríficos, filiales de molinos nacionales e internacionales, así como otras plantas agroindustriales de alcance nacional. Se suma, en la mayor parte de los casos, la presencia de microempresas y pequeñas firmas familiares-semiartesanales (panaderías, fábricas de pastas frescas, etc.) orientadas a sus mercados locales/zonales así como algunos establecimientos integrados a 
la actividad primaria (tambos, chacinados, miel, quesos, etc.) que funcionan con una mínima dotación de trabajadores o constituyen la base de ocupación y/o complementación de ingresos de explotaciones familiares. En los centros para-agrarios, aunque de mucha menor magnitud, se encuentran las funciones vinculadas con la provisión de insumos, agroservicios (acopio, reparación de maquinarias y herramientas, abastecimiento) comercios, y servicios personales para el abastecimiento de estas comunidades. Se trata de localidades o pueblos más pequeños cuya importancia, a los fines de esta tipificación, es el proceso de crisis económica y "vaciamiento" poblacional que atraviesan desde hace algo más de dos décadas.

Está claro, entonces, que no todos los centros presentan el mismo grado de dependencia respecto al hinterland rural-agrario, ni el mismo tipo de vinculaciones. Siguiendo estos criterios, en el Cuadro 7 se asocian elementos de la propuesta de Berdegué et al. (2001) centrada en las fuentes que motorizan el empleo rural no agrícola.

El estudio del PROINDER-IICA (2006) da cuenta de un total de 31.184 pequeños productores agropecuarios (PPA) en el total de partidos provinciales contemplados aquí, de los cuales casi un $24 \%$ desarrolla actividades fuera de la explotación, dentro o fuera del sector agropecuario. La proporción es similar entre los que realizan tareas relacionadas con la actividad propia y los que se desempeñan en actividades diferentes. Si se comparan estos indicadores con los que se registran a nivel nacional, el dato más interesante es que alrededor del 55\% de los PPA pluriactivos nacionales trabaja como asalariado, mientras que a nivel provincial o de región pampeana sólo representan un 37\% y 35\% respectivamente. No hay diferencias significativas entre los que trabajan por un salario dentro y fuera del sector a nivel provincial o de región pampeana, mientras que a nivel nacional un $62 \%$ de los que trabajan por un salario lo hace fuera del sector.

Visto por regiones, surgen algunos datos ilustrativos: las regiones con mayor incidencia de la pluriactividad en PPA son la MxNO, la GCSal y la $\mathrm{MxC}$. En las regiones mixtas del centro y noroeste, junto a la urbanizada del NE, es donde se presenta la mayor proporción de pluriactividad extrasectorial. Un estudio reciente sobre los productores familiares bonaerenses también presenta evidencias asociadas a la heterogeneidad territorial de las estrategias de pluriactividad. En un partido agrícola como Tres Arroyos: "el ingreso extrapredial como fuente principal no fue un dato relevante, ya que solamente un $14 \%$ de los productores lo señalaron como determinante de sus ingresos; en los productores familiares fue aún menos significativo". En cambio, en Azul -zona ganadera de la cuenca del Salado-, "el ingreso extrapredial era muy relevante, ya que el $45 \%$ de los productores declararon que era la principal fuente de sus ingresos". No obstante, en su composición se revela que parte de estos ingresos "provenían de ocupaciones de baja remuneración (pequeños comerciantes, empleados, tareas rurales, etc.) o pasividades". Pergamino (zona núcleo agrícola del norte) muestra, por su parte, la incidencia del trabajo por cuenta propia o empresario con un leve predominio de las ocupaciones desempeñadas dentro del sector agropecuario, mientras en el partido de Luján (dentro del cordón metropolitano del NE), "el 38\% de los productores declaró que sus ingresos eran preferentemente extraprediales" (González, 2005, p. 76-78 y 105).

\section{Nuevos y viejos ámbitos para la governance rural}

En el primer acápite de este trabajo se ha señalado que el enfoque de DTR enfatiza en la necesidad de reconstrucción y fortalecimiento de la institucionalidad rural sobre la base de diferentes organizaciones de la sociedad civil y el partenariato público-privado. En otros términos, plantea la complementariedad y adecuación del marco institucional para lograr la participación y canalización de las iniciativas locales, sociales y privadas. En esta línea, el enfoque pone el acento en (De Janvry y Sadoulet, 2001; BID, 2005) ${ }^{9}$ :

el protagonismo de las organizaciones de la sociedad civil y los gobiernos locales.

2 La propuesta para la Estrategia de Desarrollo Rural de Argentina (RIMISP, 2006) sigue, en términos generales, estos lineamientos. 
la descentralización municipal como instrumento potencialmente efectivo para la implementación de planes y programas de DR

¿Cómo se motorizan estos procesos? o, desde una pregunta más específica, ¿̨hay un modelo de gestión institucional para inducir este cambio de rumbo?

\section{Los gobiernos locales}

El énfasis en el rol de los gobiernos locales no es novedoso. Sin duda, los cambios en las reglas del juego que acompañaron a las políticas de liberalización y desregulación en el marco del proceso de "ajuste estructural", tuvieron una decisiva influencia en las propuestas de descentralización territorial y su tendencia ascendente en el campo normativo.

Más recientemente, la visión de un papel más prominente de los gobiernos locales se ha instalado a través de las distintas vertientes teóricas del desarrollo endógeno local. Una vez más, bajo la inspiración de experiencias exitosas en países desarrollados -fundamentalmente europeos y, en muchos casos, con larga trayectoria en autonomías locales regionales-, este principio orientador aparece como normativa básica que tiene aceptación generalizada. Entre lo que debería ser y lo que es se plantea, sin embargo, una gran distancia, sobre todo cuando se trata de los estados locales en escenarios periféricos; Hilhorst (1997, p. 19) sistematiza los problemas más habituales a partir de evidencias en ciudades secundarias:

inadecuación de los fondos para encarar necesidades locales y asignación inapropiada de gastos; el gasto recurrente (particularmente salarios) toma una porción considerable del presupuesto;

los ingresos per cápita son generalmente muy bajos; los mecanismos de captación de ingresos son inefectivos; no hay o son muy débiles los mecanismos para definir o promover actividades económicas, y faltan mecanismos legales que puedan constituir la base para gravar con impuestos a los actores locales;

bajos niveles de desarrollo económico limitan las posibilidades de una descentralización efectiva y, asimismo, las capacidades de los gobiernos locales. Esto puede incluso reflejarse en el status que pueden tener frente a los ministerios que supervisan el funcionamiento. Las ciudades más grandes tendrán una posición mejor que aquellas pequeñas;

lo anterior juega un rol tan significativo que puede hablarse de la presencia de otro círculo vicioso del desarrollo espacial. Asimilando el argumento de Myrdal, en torno al movimiento de los recursos privados, "las diferencias existentes entre las autoridades locales tenderán a ocasionar flujos de recursos públicos en la misma dirección, reforzándose mutuamente y tendiendo por lo tanto a fortalecer las estructuras espaciales existentes" (p. 20).

Cavarozzi (2005, p. 5) llega a conclusiones similares al analizar las condiciones de los municipios argentinos para intervenir en la Estrategia de DTR: "debilidad del sector municipal para la formulación y ejecución de políticas. Esta debilidad, especialmente manifiesta en una baja participación en el conjunto del gasto público y escaso desarrollo de la capacidad burocrática instalada”. En Buenos Aires, el autor reconoce:

i) que está en el promedio de las provincias en términos de descentralización económica y financiera (especialmente el inmobiliario rural);

ii) que existirían capacidades efectivas para asumir la descentralización dado que los municipios poseen una alta autonomía financiera, una trayectoria descentralizante del Estado entre moderada y alta, y un alto desarrollo burocrático (sin grandes diferencias entre Gran Buenos Aires, Gran La Plata y el Interior bonaerenses, e incluso a favor de éste);

iii) en este marco, los municipios del interior son relativamente menos autónomos financieramente pero tienen un gasto per cápita que triplica al del Conurbano y lo duplica en la relación agente/población.

\section{Organizaciones agro-rurales}

Durante las dos últimas décadas surgieron múltiples formas de organización de las sociedades rurales, fortalecidas a su vez por la propia lógica del 
accionar público, con una expansión significativa de las de orientación económica, relacionadas con los objetivos de: reconversión productiva y nuevos mercados; integración agroindustrial; financiamiento alternativo; comercialización comunitaria; organización de servicios de asistencia técnica, capacitación y transferencia tecnológica; identidad y proyectos de desarrollo local y regional. Estudios recientes en Argentina dan cuenta, también, de la variada gama de organizaciones rurales (territoriales y/o de trama productiva) que han tenido el impulso de la intervención de agentes gubernamentales y no gubernamentales o ambos simultáneamente. (Manzanal, 2003; Manzanal et al., 2006; Gutman et al., 2004; Rossi y León, 2005, entre otros).

En el caso pampeano, Neiman et al. (2006), retomando reflexiones efectuadas por Lattuada (1995), señalan que la red institucional de representación de intereses del sector agropecuario: "se hizo más amplia y heterogénea pero también más específica en cuanto a sus demandas; los aspectos críticos de esta transición tienen que ver con el pasaje de formas de organización que se basaban en la presión sobre el aparato estatal a otras donde deben defender a sus asociados de los demás intereses privados" (p. 182).

Así, entre las nuevas organizaciones se destacan las asociaciones por cadena (de girasol, de soja), que actúan como canales de difusión del nuevo paquete tecnológico en las producciones extensivas, y las cooperativas o asociaciones de producciones intensivas (apícolas, cunícolas, hortícolas, etc.). Existen, asimismo, iniciativas de gestión de problemáticas rurales que han motorizado acuerdos público-privados. El caso de los distritos de Azul y Olavaria, para el financiamiento de infraestructura rural, ilustra este tipo de experiencias. Las dos Municipalidades, la Sociedad Rural y las Cooperativas Eléctricas de ambos distritos, junto a dos empresas cementeras (Cemento Avellaneda y Loma Negra) implementan un proyecto para pavimentar unos 1.000 kilómetros de caminos rurales. En el desarrollo de esta experiencia se observa: i) acuerdo y coordinación entre los dos gobiernos locales (negociación con el gobierno provincial, gestión de las alianzas privadas); ii) esquema participativo para los potenciales productores beneficiados (determinación de las trazas, mejoras, valorización); iii) esquema de financiamiento (fideicomiso); iv) potencial proyección del modelo articulación público-privada para la expansión del sistema de electrificación rural en las áreas afectadas.

En el distrito de Cañuelas el municipio (en particular las áreas de habilitaciones y bromatología) y un grupo de microemprendedores agroindustriales y productores primarios gestaron un proyecto común para la venta de productos locales en el radio céntrico de la ciudad y en el predio ferial ubicado estratégicamente en una de las vías de acceso del cordón metropolitano.

Otra experiencia, de diferente perfil por el tipo de actores que articula, es la de la Colonia Ferrari (Partido de Maipú). En este caso, una ONG Asociación Jaime de Nevares- está desarrollando un metodología de intervención social para la ocupación del territorio rural, con el objetivo de que se convierta en experiencias replicables para un número creciente de familias que puedan vivir y evolucionar de su trabajo en el campo. La propuesta implica no sólo los aspectos tecnológicos necesarios para una producción de subsistencia y reproducción de las familias, sino también las cuestiones sociales y culturales del medio donde se realiza la intervención, buscando un modo alternativo de producción agro-rural a través de acuerdos con el Instituto Nacional de Tecnología Agropecuaria (INTA) y el Ministerio de Desarrollo Humano de la Provincia. En la implementación se prevé la conformación de una cooperativa entre las familias colonas y los vecinos (en especial los trabajadores rurales), el desarrollo de un sistema productivo comunitario y la creación de redes de articulación con otros grupos vinculados a la asociación, localizados en Mar del Plata y Florencio Varela.

\section{Otras dinámicas organizativas}

Entre las más recientes experiencias de fortalecimiento del entramado institucional local, inducido por políticas territoriales específicas, se destaca la de los Pactos Territoriales que han sido implementados en el marco de estrategias elaboradas por la Unión Europea. "Los Pactos territoriales son acuerdos entre sujetos públicos y privados, para ejecutar programas integrados de inversiones industriales, agroindustriales y de servicios. [...] el objetivo es promover el desarrollo de la región 
a través del establecimiento de una alianza local” (FAO, 2003, p. 22).

Alrededor de esta inducción se combinan varios ejes de intervención. Algunos programas sociales de reciente implementación en la provincia, como Trabajo Dignifica y Pueblos, han comenzado a avanzar en esta metodología accionando e induciendo la conformación de mesas de actores y la concertación en torno a proyectos locales. La conformación de fondos municipales, desde una visión asistencial-productiva y orientados a muy pequeños emprendedores locales, desempleados y/o intervenciones destinadas a paliar problemas de pobreza local (rural y/o urbana), se combinan con otras fuentes de subsidios (provincia, nación, agencias internacionales) y suelen articularse con programas de capacitación y asistencia técnica.

Por su parte, en los últimos años se ha difundido un amplio rango de instituciones que operan a nivel local:

Agencias de desarrollo. Particularmente en las ciudades medianas y grandes de las diferentes regiones agro-productivas, modeladas en la línea del recetario generado por la planificación estratégica. Más allá de la efectividad o no de su accionar, se han concebido bajo el supuesto de que serán el brazo ejecutor $\mathrm{y}$, principalmente, articulador de las políticas de desarrollo económico de la ciudad y, en cierto modo, con una perspectiva bastante "desligada” del acontecer agro-rural circundante. En general, las iniciativas más próximas a este ámbito tienen que ver con el turismo rural.

Consejos municipales asesores. Con amplia difusión entre las capitales de partido, en especial aquellas de rango de tamaño menor a los 50.000 habitantes. Esta modalidad tipifica, entonces, a los distritos con mayor grado de ruralidad donde se combinan los que funcionan en el entorno de los gobiernos locales con aquellos vinculados a las estaciones experimentales del INTA localizadas en el medio rural de la región. Por su composición (representantes de las entidades de productores, de los sectores de educación y salud, otros sectores económicos locales, etc.) están más volcados a las problemáticas agrorregionales y contemplan cuestiones ligadas a los sectores sociales más vulnerables. Asimismo, suelen canalizarse las múltiples iniciativas de las comunidades locales (culturales, medioambientales, educativas, etc.) $y$, en muchos casos, se encuadran en los proyectos y/o propuestas moldeadas desde otros programas existentes (provinciales y nacionales).

- Acuerdos o asociaciones intermunicipales. Persisten unos pocos Consorcios Productivos, de los conformados en la década anterior, así como otras iniciativas (formalizadas o no) entre municipios en la búsqueda de un espacio de solidaridades locales. Dos lógicas se combinan en la inducción de estos agrupamientos territoriales: capturar ventajas de escala (económica-territorial) para promover exportaciones y desarrollar activos específicos (marca regional, laboratorios de certificación de calidad, equipamiento); una herramienta de lobby para fortalecer la interacción pública local-provincial.

Desde una visión cuantitativa, podría argumentarse que el medio rural bonaerense detenta un entramado institucional denso. No obstante, asumiendo la fuerte heterogeneidad entre las experiencias locales, cabe advertir la necesidad de revisar otro conjunto de aspectos relacionados con la calidad y complejidad de las vinculaciones. Como señala Amin (2000, p. 58) visualizar, por un lado, "la calidad de los vínculos derivados de las economías de asociación, por su impacto sobre la circulación de información informal, innovación y conocimiento...". Por otro lado, asumir que "el desafío político para las regiones menos favorecidas es encontrar una forma de sustituir sus relaciones tradicionales de jerarquía y dependencia (grandes empresas, provisión estatal, conexiones familiares) por vínculos de reciprocidad entre los agentes económicos y las instituciones".

Las redefiniciones en curso no sólo remiten a las relaciones entre el aparato público local y la sociedad civil sino a las asociadas con el capital relacional gestado en las comunidades locales. Si bien es cierto que se han trastocado las formas tradicionales de entrelazamiento con los gobier- 
nos municipales, esta tendencia aún está lejos de disminuir los vínculos paternalistas o clientelares. Una serie de evidencias, si bien poco formalizadas, también sugieren problemas ligados a la calidad de las interrelaciones en el seno de las organizaciones de productores, pequeños empresarios y comerciantes. En tal sentido, parece oportuno aludir a dos reflexiones que realiza Manzanal (2006, p. 41) a partir de estudios realizados en otras regiones del país. Una, en relación a la naturaleza de las comunidades locales, en tanto unidades no cohesionadas ni semejantes. Dicho de otro modo, "el conflicto entre los actores locales (latente o evidente) como una realidad indiscutible de cualquier lugar. Es decir, el consenso no es la regla, la negociación tampoco, menos la participación, que podría decirse que está despuntando en ámbitos territoriales muy específicos". Dos, en el escenario de nueva ruralidad "los actores asumen múltiples roles simultáneamente (sea como productores, asalariados, cuentapropistas, desocupados, rentistas, jubilados) complejizando aún más los efectos sobre las formas de organización".

Por último, no puede dejar de advertirse que las potencialidades y límites de esta institucionalidad territorial -habitualmente asociados a la territorialización de ciertos impulsos productivos y/o económicos alternativos- están atadas a un contexto macrosocial y espacial marcado por la fuerte desigualdad y distorsión en la distribución de la renta y riqueza que profundizan las desigualdades sociales y territoriales.

\section{Reflexiones finales}

En el difundido enfoque del DTR, más allá de las experiencias concretas de aplicación, existe una especie de hilo argumental trazado desde dos criterios rectores: i) una visión más amplia de las economías rurales, integrando complejos rururbanos de encadenamientos de servicios e insumos relacionados con la producción y el consumo local-regional; ii) énfasis en las ocupaciones no agrícolas como fuente de ingresos adicionales de los hogares rurales pobres. En tal sentido, y desde la perspectiva de las formulaciones de propuestas de política pública, el desafío es fomentar los encadenamientos locales que retroalimenten el desarrollo agrícola con el no agrícola y viceversa.
A lo largo de estas páginas se han identificado, en la provincia de Buenos Aires, determinados factores y elementos de alta rigidez que obstruyen la concreción de ciertas combinaciones virtuosas de carácter endógeno que se plantean desde el enfoque del DTR.

La población agro-rural alcanzaba el 10\% del total de la provincia en el año 2001, y el $27 \%$ si se excluyen los partidos de la unidad territorial más urbanizada (cordones metropolitanos), considerando entonces, las 8 zonas agro-productivas donde se distribuyen las localidades o centros urbanos económicamente especializados en actividades agro-rurales. Respecto a este fenómeno interesa aquí resaltar dos cuestiones. En primer lugar, la constatación de una clara continuidad a lo largo de las últimas décadas, de un esquema económico-territorial con la agricultura como fuente principal de riqueza y acumulación. De este modo, en vastas zonas agro-rurales del interior bonaerense se plantea una especie de círculo vicioso: estructura económica fuertemente asociada a la actividad agropecuaria, y ausencia de atractivos para la radicación de nuevos emprendimientos y diversificación productiva, falta de oportunidades de empleo y expulsión o deterioro de los recursos humanos localizados (descalificación progresiva de la mano de obra, distanciamiento tecnológico de los agentes productivos, etc.). Entre otros efectos, deseconomías de aglomeración y complementación, en un marco de despoblamiento rural y desigualdad socioeconómica regional.

Como en el resto de la región pampeana, ha disminuido el número de personas ocupadas en la agricultura. Asimismo, en términos de empleo extra-predial (agrícola y no agrícola) las dinámicas parecen ser de continuidad, expansión e intensificación según tamaño y grado de diversificación del entorno rururbano Así, las regiones con mayor incidencia de la pluriactividad en los pequeños productores familiares son la MxNO, la GCSal y la $\mathrm{MxC}$, pero son las áreas mixtas del centro y noroeste, junto a la urbanizada del NE donde se presenta la mayor proporción de pluriactividad extrasectorial.

La segunda cuestión a resaltar es que el territorio bonaerense presenta, en términos generales, 
una gran inercia en su configuración. Difícilmente puede percibirse que se estén delineando patrones territoriales nuevos, capaces de alterar la polarización espacial entre el Interior y la región metropolitana bonaerense. Las incidencias recientes sugieren, aun así, algunas situaciones donde el cambio parece más intenso:

- En zonas agro-productivas en las cuales se combinan los efectos de los corredores viales, que intensifican las conexiones con la principal aglomeración provincial, y el crecimiento de las localidades costeras, como en la Cuenca del Salado.

- En la región del noreste, donde se afirman interrelaciones propias de los nuevos fenómenos urbanizadores y rururbanos (Pilar, Escobar).

- En las zonas agro-rurales que se han convertido en expulsoras de población como la mixta del noroeste y, en menor medida, la del suroeste.

- En las ciudades intermedias de la provincia, cuyo número aumenta (de 69 a 76) en el marco de un proceso continuo de migración poblacional originada en las pequeñas localidades de su región circundante.

Por último, la orientación de las actuales políticas dirigidas al medio rural bonaerense no ha perdido el énfasis "asistencial" que ha permeado el accionar durante la década anterior. Si bien contribuyen a paliar la vulnerabilidad socioeconómica de un grupo significativo de familias rurales, no cabe duda que su alcance es muy limitado para resolver problemáticas estructurales de su población objetivo (acceso a la tierra, fuentes de trabajo sustentables y sostenibles económicamente, relaciones laborales, entre las más importantes). En un contexto que denota fuertes alteraciones tanto productivas como institucionales, con políticas macrosectoriales que distan mucho de revertir los ejes de un crecimiento concentrador y excluyente, los programas inspirados en el DTR apelan a cierta dosis de voluntarismo (social y político). Como señala Lattuada et al. (2006, p. 173), este tipo de programas "resultan una cura efímera o una porción homeopática para unos pocos, si las condiciones estructurales y la política económica y sectorial resultan adversas o neutras".

\section{Referencias bibliográficas}

Amin, A. (2000). Una perspectiva institucionalista sobre el desarrollo económico regional. Cuadernos IPPUR, 14, 2, 47 - 68.

Banco Interamericano de Desarrollo, BID (2005). Perfil avanzado. Politica de desarrollo rural. Documento de circulación. Recuperado el 26 de julio de 2006, de http://idbdocs.iadb. org/wsdocs/getdocument.

Barros, C.; González Maraschio, F. \& Villarreal, F. (2005). Actividades rurales y neorrurales en un área de contacto rural-urbano. En FCE UBA (Ed.), IV Jornadas interdisciplinarias de estudios agrarios y agroindustriales, Buenos Aires, Argentina.

Berdegué, J.; Reardon, T. \& Escobar, G. (2001). La creciente importancia del empleo y el ingreso rurales no agrícolas. En R. Echeverría (Ed.) (2001), Desarrollo de las economías rurales (pp. 183-212). Washington, EE.UU.: Banco Interamericano de Desarrollo.

Berger, M. (2003). El agro en el periurbano: ¿transformación o disolución? El caso del partido de Cañuelas. En FCE UBA (Ed.), III Jornadas Interdisciplinarias de Estudios Agrarios y Agroindustriales, Buenos Aires, Argentina. (2006). Trayectorias de los actores agrarios: pluriactividad y pluriinserción en el partido de Carlos Tejedor, provincia de Buenos Aires. En G. Neiman \& C. Craviotti (Comp.), Entre el campo y la ciudad: desafios y estrategias de la pluriactividad en el agro (pp. 115-136). Buenos Aires, Argentina: Ciccus.

Calatrava, A. \& Melero, A. (2003). Aproximación a la estructura y los modelos de diversificación de la actividad empresarial en municipios rurales: análisis y tendencias en dos regiones españolas. EURE, 29, 88, 97-130.

Campolina Diniz, C. (2003). Repensando la cuestión regional brasileña: tendencias, desafíos y caminos. EURE, 29, 88, 29-54.

Carballo, C. (Coord.); Tsakoumagkos, P.; Gras, C.; Rossi, C.; Plano, J. L. \& Bramuglia, G. (2004). Articulación de los pequeños productores con el mercado: limitantes y propuestas para superarlas. Serie de Estudios e Investigaciones, 7. 
Cavarozzi, M. (2005). Experiencias municipales $y$ provinciales en la gestión del desarrollo rural. Recuperado el 5 de junio de 2006, de http:// www.rimisp.org.

Craviotti, C. (2005). Nuevos agentes en la producción agropecuaria: ¿nuevos sujetos del desarrollo rural? En G. Neiman y C. Craviotti (comp.). Entre el campo y la ciudad. Desafios y estrategias de la pluriactividad en el agro (pp. 49-68). Buenos Aires: Ciccus.

De Janvry, A. \& Sadoulet, E. (2001). La inversión en desarrollo rural es buen negocio. En R. Echeverría (Ed.) (2001), Desarrollo de las economias rurales (pp. 1-42). Washington: EE.UU.: Banco Interamericano de Desarrollo.

Delgadillo Macías, J. (2006). Dimensiones territoriales del desarrollo rural en América Latina. Problemas del desarrollo. Revista Universitaria de Economía, 37, 144, 97-120.

Dirven, M. (2001). El cluster: un análisis indispensable. Una visión pesimista. Revista de la Procuraduría Agraria, 17, 31-59.

FAO (2003). La nueva ruralidad en Europa y su interés para América Latina. Recuperado el 5 de julio de 2006, de http//www.fao.org.

García Ramón, M.; Tulla, I.; Pujol, A. \& Valdovinos Perdices, N. (1995). Geografía Rural, Espacios y Sociedades, 10.

González, M. (Coord.) (2005). Productores familiares pampeanos: hacia la comprensión de similitudes y diferenciaciones zonales. Buenos Aires, Argentina: ASTARLIB Cooperativa Editora.

Gorenstein, S. (2000). Rasgos territoriales en los cambios del sistema agroalimentario pampeano (Argentina). EURE, 26, 78, 51-76. (2005, agosto). Aportes al debate sobre la cuestión regional argentina: conceptos, instrumentos y caminos para la construcción de propuestas. Ponencia presentada en Hacia el Plan Fénix II: en vísperas del segundo centenario, Universidad de Buenos Aires, Argentina.

Gorenstein, S.; Napal, M.; Barbero, A. \& Olea, M. (2006). Diagnóstico y propuestas para la elaboración de la Estrategia de Desarrollo Rural de la Provincia de Buenos Aires. Documento de trabajo PROINDER/SAGPyA/Ministerio de Asuntos Agrarios de la Provincia.
Gutman, G.; Iturregui, M. E. \& Filadoro, A. (2004). Propuestas de formulación de políticas para el desarrollo de tramas productivas regionales. El caso de la lechería caprina en Argentina. Serie Estudios y Perspectivas CEPAL, 21.

Hilhorst, J. G. M. (1997). Desarrollo local/regional e industrialización. EURE, 22, 68, 7-28.

INDEC (1988; 2002). Censo Nacional Agropecuario.

(1991; 2001). Censo Nacional de Población.

Klink J. (2001). A cidade-regio. Regionalismo e reestructuraço no grande $A B C$ paulista. San Pablo, Brasil: DP\&A.

Lattuada, M.; Renold, J.; Binolfi, L \& De Biasi, A. (2006). Limitantes al desarrollo territorial rural en contextos de políticas sectoriales neutras o negativas. En M. Manzanal, G. Neiman \& M. Lattuada (2006), Desarrollo rural. Organizaciones, instituciones y territorios (pp. 153-176). Buenos Aires, Argentina: Ciccus.

Manzanal, M. (2003). Instituciones y gestión del desarrollo rural en Argentina. Realidad Económica, 197, 92-115.

(2005). Modelos de intervención de los proyectos de desarrollo rural en Argentina a partir de 1995. Documento disponible en http://www.rimisp.org/seccion. php?seccion $=477$.

(2006). Regiones, territorios e institucionalidad del desarrollo Rural. En M. Manzanal, G. Neiman \& M. Lattuada (2006), Desarrollo Rural. Organizaciones, instituciones $y$ territorios (pp. 21-50). Buenos Aires, Argentina: Ciccus.

Méndez, R. (2002). Innovación y desarrollo territorial: algunos debates recientes. EURE, $28,84,63-84$.

(2006, mayo). Del distrito industrial al desarrollo territorial: estrategias de innovación en ciudades intermedias. Ponencia presentada en IX Seminario de la Red Iberoamericana de Investigadores en Globalización y Territorio (RII), Bahía Blanca, Argentina.

Neiman G.; Berger, M.; Arroñade, S.; Fabio, F.; Goldfarb, L.; Karol, A.; Mingo, E. \& Neiman, M. (2006). Diversidad de las formas de representación de intereses entre organizaciones de pequeños productores del agro argentino: base 
social, reivindicaciones y articulaciones. En M. Manzanal, G. Neiman \& M. Lattuada (2006), Desarrollo rural. Organizaciones, instituciones $y$ territorios (pp. 177-210). Buenos Aires, Argentina: Ciccus.

Neiman, G. \& Craviotti, C. (Comp.) (2005). Entre el campo y la ciudad: desafios y estrategias de la pluriactividad en el agro. Buenos Aires, Argentina: Ciccus.

OCDE (1994). Créer des indicateurs ruraux pour étayer la politique territoriale. Paris: OCDE.

Piñeiro, M. (2001). Importancia del sector agroalimentario. En R. Echeverría (Ed.) (2001), Desarrollo de las economías rurales (pp. 71-102). Washington, EE.UU.: Banco Interamericano de Desarrollo.

PNUD (2002). Hacia una integración cooperativa y solidaria del territorio nacional. Cuaderno de Competitividad y Desarrollo Humano. Recuperado el 7 de julio de 2006, de http://www. pnud.org.ar.

PROINDER-Dirección de Desarrollo Agropecuario-IICA (2006). Los pequeños productores en la República Argentina. Importancia de la producción agropecuaria y el empleo en base al Censo Nacional Agropecuario 2002. Serie Estudios e Investigaciones, 10.

Rimisp-Centro Latinoamericano para el Desarrollo Rural (2006). Propuesta para una estrategia de Desarrollo Rural de la Argentina. Recuperado el 16 de julio de 2006 de http://www.rimisp.org.

Rossi, C. \& León, C. (2005). Temas fundamentales en la inserción de pequeños productores en cadenas comerciales para una Estrategia de Desarrollo Rural. Documento del proyecto RIMISP-SAGPyA. Recuperado el 21 de julio de 2006, de http://www.rimisp.org/.

Schejtman, A. \& Berdegué, J. (2004). Desarrollo territorial rural. Recuperado el 25 de abril de 2006, de http://www.rimisp.org.

Silva, J. Graziano da (1998). A nova dinâmica da agricultura brasileira. Campinas, Brasil: Instituto de Economía, UNICAMP.

Tort, M. I \& Román, M. (2005). Explotaciones familiares, diversidad de conceptos y criterios operativos. En M. González (Coord.), Productores familiares pampeanos: hacia la comprensión de similitudes y diferenciaciones zonales (pp. 35-66). Buenos Aires, Argentina: ASTARLIB Cooperativa Editora. 